\title{
ONE-DIMENSIONAL COMPOUNDS-I IODINE OXIDATION OF BIS(ORTHOPHENYLENEDIIMINE) COMPLEXES OF NICKEL(II)
}

\author{
YEE-MIN WUU and SHIE-MING PENG* \\ Department of Chemistry, National Taiwan University, Taipei. Taiwan, Republic of China
}

(Received 30 August 1978; in revised form 2 January 1979)

\begin{abstract}
Oxidation of Ni(opd $)_{2}$ (opd $=o$-phenylenediimine) with iodine results in the formation of a series of new complexes of $\mathrm{Ni}(\mathrm{opd})_{2} \mathrm{I}_{x}(x=0.97,2.57$ and 5.79) stoichiometry. These compounds were characterized by elemental analyses and spectroscopic means; they all form semiconducting solids with specific conductivity of $10^{-7} 10^{-4} \Omega^{-1} \mathrm{~cm}^{-1}$.
\end{abstract}

\section{INTRODUCTION}

In recent years there has been a great interest in mixedvalent and partially oxidized chain inorganic complexes due to the observation of a variety of anisotropic properties associated with the one-dimensionality of the system $[1,2]$. Most of the one-dimensional complexes studied to date have contained infinite stacks of closely packed planar molecules and a nonintegral formal oxidation of the constituents, i.e. $\mathrm{K}_{2} \mathrm{Pt}(\mathrm{CN})_{4} X_{0.3} \cdot 3 \mathrm{H}_{2} \mathrm{O}(X=$ $\mathrm{Cl}, \mathrm{Br})[3], \mathrm{NiPcl}_{x}(\mathrm{Pc}=$ phthalocyanine, $x=0.56,1.0$, and 1.74) [4], Ni(omtbp) $I_{x}$ (omtbp = octamethyltetrabenzoporphyrin, $x=1.05$ and 2.91) [5], and $\mathrm{Ni}(\mathrm{dpg})_{2} \mathrm{I}_{x}$ $(\mathrm{dpg}=$ diphenylglyoximato, $x=1.02)[6,7]$.

Iodine oxidation of bis $(o$-phenylenediimine) complex of $\mathrm{Ni}(\mathrm{II})$, I, was reported to yield only dark iodide complex of $\mathrm{Ni}(\mathrm{opd})_{2} \mathrm{I}$ by Balch and Holm[8]. Miles and<smiles>c1ccc2c(c1)NN(N1CNc3ccccc31)N2</smiles>

$\circ$

I

Wilson [9] synthesized the semiconducting salts from bis(o-phenylenediimine) nickel and related cations with several bis(1,2 - dithiolato) metal anions. In this paper we present the preparation and characterization of a series of new complexes from iodine oxidation of the bis $(o-$ phenylenediimine) complex of $\mathrm{Ni}(\mathrm{II})$.

\section{EXPERIMENTAL}

Ammonia water, bromine water, nickel(II) chloride, $o$-phenylenediamine, acetone, methanol, and tetrahydrofuran were obtained commercially without further purification. Elemental analyses are reported as obtained from Chun-Shan Institute of Science and Technology. Each sample was analysed at least twice and the average is reported. X-Ray powder diffraction data were obtained on a Toshiba ADP-301 diffractometer. IR spec$\operatorname{tra}(\mathrm{KBr})$ were recorded on a Perkin-Elmer 137 spectrometer. Electronic spectra were recorded on a Cary 14 or Beckman DG-B spectrometer. EPR data were obtained with a Varian E9 spectrometer. Electric conductivity measurements were performed on pellets pressed at $400 \mathrm{psi}$ of dimension about $1 \mathrm{~mm}$ using locally designed two-electrode apparatus.

\footnotetext{
*Author for correspondence
}

Preparation of materials. Ni(opd) $)_{2}[8,9]$ (opd $=\mathrm{C}_{6} \mathrm{H}_{4}(\mathrm{NH})_{2}$ ). A solution of $10 \mathrm{~g}$ of nickel chloride hexahydrate in $30 \mathrm{ml}$ of water and $30 \mathrm{ml}$ of concentrate aqueous ammonia was added to a solution of $6 \mathrm{~g}$ of $o$-phenylenediamine in $800 \mathrm{ml}$ warm water. This mixture was stirred in an open beaker for $24 \mathrm{hr}$. A deep blue precipitate formed and was collected by filtration, washed with water, acetone and dried. The yield of this crude product was $70 \%$. Purification was accomplished by soxhlet extraction using acetone. The first extracts of a greenish color were discarded. Once a deep blue extract was obtained, the extraction was allowed to proceed for several days. Fine crystals, ranging in surface color from deep blue to metallic greenish gold, formed during the extraction. These were collected, washed with acetone and vacuum dried. The yield of these fine crystals was $10 \%$.

$\mathrm{Ni}(\mathrm{opd})_{2} \mathrm{I}_{0.97}[8]$. A solution of $0.343 \mathrm{~g}(2.70 \mathrm{mg}$-atoms $)$ of iodine in $70 \mathrm{ml}$ acetone was added slowly to a slurry of $0.665 \mathrm{~g}(2.45 \mathrm{~m}$ mole) of $\mathrm{Ni}(\mathrm{opd})_{2}$ in $80 \mathrm{ml}$ acetone. After $20 \mathrm{hr}$ of stirring, the original deep blue crystals were transformed into a brown-black powder which was collected by filtration, washed with acetone. and vacuum dried. Anal. Calc.: C, 36.50: H. 3.04: I. 31.32. Found: C, 36.00(9); H, 3.21(5); I, 30.89(4).

Ni(opd $)_{2} \mathrm{I}_{2.57}$. A solution of $1.56 \mathrm{~g}$ (12.25 gm-atoms) of iodine in $80 \mathrm{ml}$ of acetone was added slowly to a slurry of $0.665 \mathrm{~g}(2.45 \mathrm{~m}$ mole) of Ni(opd $)_{2}$ in $70 \mathrm{ml}$ of acetone. After $3 \mathrm{hr}$ of stirring, the original deep blue crystals were transformed into black powder which was collected by filtration, washed with acetone twice, and vacuum dried. Anal. Calc.: C, 24.11; H, 2.01; I, 54.62. Found: C. 24.58(4); H, 1.90(9): I, 55.70(14).

$\mathrm{Ni}(\mathrm{opd})_{2} \mathrm{I}_{5.79}$. A solution of $3.12 \mathrm{~g}$ (24.5 mg-atoms) of iodine in $130 \mathrm{ml}$ of THF was added slowly to a slurry of $0.665 \mathrm{~g} 12.45 \mathrm{~m}$ mole) of $\mathrm{Ni}(\mathrm{opd})_{2}$ in $70 \mathrm{ml}$ of THF. After $1 \mathrm{hr}$ of stirring, the original deep blue crystals were transformed into a gray black powder which was collected by filtration, washed with acetone twice, and vacuum dried. Anal. Calc.: C, 14.31; H. 1.19; I, 73.06. Found: C, 14.36(19); H. 1.46(5); I. 73.35(13).

$\mathrm{Ni}(\mathrm{opd})_{2}$ reacted with bromine. A solution of $10 \mathrm{ml}(2.14 \mathrm{~m}$ mole) of bromine water was added slowly to a slurry of $0.542 \mathrm{~g}$ ( $2 \mathrm{~m} \mathrm{~mole}$ ) of $\mathrm{Ni}(\mathrm{opd})_{2}$ in $50 \mathrm{ml}$ of acetone. After $3 \mathrm{hr}$ of stirring. the deep blue crystals were transformed into a black powder which was collected by filtration, washed with acetone, and vacuum dried. The elemental analysis were done with nonreproduceable data. The ratios of $\mathrm{C} . \mathrm{H}, \mathrm{N}$ vary in each analysis.

\section{RESULTS AND DISCUSSION}

Careful evaluation of the elemental analysis data revealed that in addition to the previously described formally stoichiometric $1: 1 \mathrm{I} / \mathrm{Ni} \mathrm{Ni(opd})_{2} \mathrm{I}[8]$, a series of non-stoichiometric complexes can be isolated. A maximum $\mathrm{I} / \mathrm{Ni}$ ratio of 5.79 was observed. This stoichiometry was confirmed by different batches of preparations and four times of elemental analyses. A slightly excess of 
iodine was used to prepare those complexes, i.e. $\mathrm{I} / \mathrm{Ni}$ ratio of 1.1 for $\mathrm{Ni}(\text { opd })_{2} \mathrm{I}_{0.97}, 5.0$ for $\mathrm{Ni}$ (opd $)_{2} \mathrm{I}_{2.57}$, and 10 for $\mathrm{Ni}(\mathrm{opd})_{2} \mathrm{I}_{5.79}$. Their extremely low solubility and low stability in solution rendered purification difficult. All complexes are stable in solid phase for months. Oxidation of $\mathrm{Ni}(\mathrm{opd})_{2}$ with large excess of iodine or equivalent amount of bromine led to the decomposition of Ni(opd) 2 The decomposed products which were brown to black in color, did not diffract X-ray well and had poorly resolved IR spectra were not pursued.

It was reported $[9,10]$ that neutral bis $(o-$ phenylenediimine) nickel(II) was polymorphic, one crystalline form appearing to be dark green and the other gold. Both forms, which have identical IR spectra, have been isolated. X-Ray powder patterns which are presented in Table 1 indicate the dark green form and gold form have different structures and the former appears to be identical with that on which Hall and Soderberg performed a single crystal structure determination[10]. Because of identical $d$ for several peaks, samples of both forms prepared may appear to be impure or have cell constants which result in same $d$ values.

Iodine oxidation of dark green form of $\mathrm{Ni}(\mathrm{opd})_{2}$ were characterized by X-ray powder diffraction. All appear to have different structures, to be homogeneous in nature, most of all, they are not mixtures of $\mathrm{Ni}(\mathrm{opd})_{2}$ and $\mathrm{Ni}(\text { opd })_{2} \mathrm{I}_{\max }$.

The IR spectra of this series of the complexes vary significantly. All exhibit a N-H strech at $3250 \mathrm{~cm}^{-1}$, and $\mathrm{C}=\mathrm{C}, \mathrm{C}=\mathrm{N}$ streches in the $1400-1600 \mathrm{~cm}^{-1}$ region. The characteristic region of these compounds is 740
$900 \mathrm{~cm}^{-1}$, the tentative assignment of those bands is out of plane bending of phenylene $\mathrm{C}-\mathrm{H}$. The unoxidized form of $\mathrm{Ni}(\mathrm{opd})_{2}$ has a strong absorption at 730 , $745 \mathrm{~cm}^{-1}$, where $\mathrm{Ni}(\text { opd })_{2} \mathrm{I}_{0.97}$ at $790 \mathrm{~cm}^{-1}, \mathrm{Ni}(\text { opd })_{2} \mathrm{I}_{2.57}$ at $770 \mathrm{~cm}^{-1}$, and $\mathrm{Ni}(\mathrm{opd})_{2} \mathrm{I}_{5.79}$ at $820,870 \mathrm{~cm}^{-1}$. Samples prepared from $\mathrm{I} / \mathrm{N}$ ratio of $0.5,2.0$, or 6.0 have IR absorptions which are characteristics of $\mathrm{Ni}(\mathrm{opd})_{2}$ and $\mathrm{Ni}$ (opd) $)_{2} \mathrm{I}_{0.97}, \mathrm{Ni}(\mathrm{opd})_{2} \mathrm{I}_{0.97}$ and $\mathrm{Ni}(\mathrm{opd})_{2} \mathrm{I}_{2.57}, \mathrm{Ni}(\mathrm{opd})_{2} \mathrm{I}_{2.57}$ and $\mathrm{Ni}(\mathrm{opd})_{2} \mathrm{I}_{5.79}$ respectively. This again indicates the homogeneity of the nonstoichiometric complexes, $\mathrm{Ni}$ (opd) ${ }_{2} \mathrm{I}_{x}(x=0.97,2.57$, and 5.79).

All complexes are intensely colored in the solid and solution phases. The electronic spectra of $\mathrm{Ni}(\mathrm{opd})_{2} \mathbf{I}_{\boldsymbol{x}}$ are given in Table 2 . These spectra are dominated by intense charge transfer bands in the visible and UV portions of the spectra. No detailed assignment will be made due to the overlap of ligand field and charge transfer absorptions.

All of the samples including unoxidized $\mathrm{Ni}(\mathrm{opd})_{2}$ yield EPR signals at solid state. The signals of $g$ values near the free-electron value $(2.0023)$ with about $25 \mathrm{G}$ width may indicate an essentially ligand based character of the odd electron. The signal of neutral complex, Ni(opd $)_{2}$, is not understood and may be due to a small impurity of the cationic species. It should be noted that a large number of diamagnetic phthalocyanine, including $\mathrm{Ni}$ phthalocyanine, give sharp isotropic signals. The origin of these "radical" is still not well known[11].

The structure of unoxidized $\mathrm{Ni}$ (opd) 2 has a stack packing structure with a long $\mathrm{Ni}-\mathrm{Ni}$ distance, $4.65 \AA$. However the solid state spectrum of $\mathrm{Ni}(\mathrm{opd})_{2}$ is different

Table 1. X-Ray powder pattern data for $\mathrm{Ni(opd})_{2} \mathrm{I}_{x}$

\begin{tabular}{|c|c|c|c|c|}
\hline \multirow{2}{*}{$\begin{array}{l}\mathrm{Ni}(\mathrm{opd})_{2} \\
\text { Darkgreen }\end{array}$} & $\mathrm{Ni}(\mathrm{opd})_{2}$, & \multicolumn{2}{|c|}{$\mathrm{Ni}(\mathrm{opd})_{2} \mathrm{I}_{.97} \mathrm{Ni(opd)}{ }_{2} \mathrm{I}_{2.57}$} & \multirow[t]{2}{*}{$\mathrm{Ni}(\mathrm{opd})_{2} \mathrm{I}_{5.79}$} \\
\hline & Gold form & & & \\
\hline $12.804(100)$ & )$^{a, b_{12} .804(100)^{2}}$ & $10.276(100)$ & ${ }^{a} 12.621(65)^{a}$ & $9.403(100)^{a}$ \\
\hline $6.414(12)$ & $6.460(28)$ & $6.191(42)$ & $9.403(18)$ & $7.400(17)$ \\
\hline $4.597(1.6)$ & $5.826(17)$ & $5.275(25)$ & $8.187(20)$ & $5.536(16)$ \\
\hline $4.309(40)$ & $4.620(35)$ & $5.094(20)$ & $5.244(42)$ & $4.980(65)$ \\
\hline $4.208(39)$ & $4.330(45)$ & $4.620(58)$ & $4.718(100)$ & $4.482(60)$ \\
\hline $3.737(50)$ & $4.228(32)$ & $4.189(22)$ & $4.020(85)$ & $4.112(15)$ \\
\hline $3.676(25)$ & $3.737(50)$ & $4.075(90)$ & $3.932(60)$ & $4.038(15)$ \\
\hline $3.588(12)$ & $3.588(42)$ & $3.800(20)$ & $3.768(46)$ & $3.438(77)$ \\
\hline $3.119(16)$ & $3.425(10)$ & $3.676(16)$ & $3.207(22)$ & $3.325(45)$ \\
\hline $3.057(6)$ & $3.207(9)$ & $3.588(38)$ & $3.163(8)$ & $3.253(10)$ \\
\hline $2.939(6)$ & $3.119(42)$ & $3.451(85)$ & $3.057(22)$ & $2.997(50)$ \\
\hline $2.391(25)$ & $3.057(16)$ & $3.400(35)$ & $2.939(9)$ & $2.948(26)$ \\
\hline $2.022(13)$ & $2.958(23)$ & $3.207(14)$ & $2.562(8)$ & $2.920(50)$ \\
\hline $1.980(20)$ & $2.391(14)$ & $3.077(7)$ & $2.514(9)$ & $2.487(30)$ \\
\hline $1.774(8)$ & $2.297(13)$ & $2.997(18)$ & $2.195(10)$ & $2.441(20)$ \\
\hline $1.745(9)$ & $2.253(14)$ & $2.902(12)$ & $1.972(8)$ & $2.379(6)$ \\
\hline \multirow[t]{7}{*}{$1.721(8)$} & $2.226(5)$ & $2.839(10)$ & & $2.314(18)$ \\
\hline & $2.150(5)$ & $2.745(20)$ & & $2.269(7)$ \\
\hline & $2.022(5)$ & $2.534(20)$ & & $2.231(12)$ \\
\hline & $1.980(5)$ & $2.253(12)$ & & $2.150(32)$ \\
\hline & $1.844(6)$ & $2.221(14)$ & & $2.066(17)$ \\
\hline & $1.777(5)$ & $2.031(12)$ & & $1.777(12)$ \\
\hline & & $1.997(14)$ & & \\
\hline
\end{tabular}

a. Filtered $\mathrm{Cu}-\mathrm{K}_{\alpha}$ radiation was used, peak was reported as $\mathrm{d}$ in $\AA$, relative intensity in parentheses.

b. The powder pattern is consistent with following cell parameters [10]: $a=5.845, b=7.485, c=25.27, \alpha=\gamma=$ $90^{\circ}, \beta=90^{\circ} 10^{\prime}$. 
Table 2. The electronic spectra and conductivity parameters for Ni(opd $)_{2} I_{x}$

\begin{tabular}{|c|c|c|}
\hline Compound & $\begin{array}{l}\text { Electronic Absorptions } \\
\text { in DMSO }\end{array}$ & $\begin{array}{l}\text { Room Temp Conductivity } \\
\Omega^{-1} \mathrm{~cm}^{-1}\end{array}$ \\
\hline $\mathrm{Ni}(\mathrm{opd})_{2}$ & $\begin{array}{l}782(4450, \mathrm{sh})^{\mathrm{a}}: 732(5900) ; 645(3250) ; 560(1700, \mathrm{sh}) ; \\
510(1550) ; 445(1600, \mathrm{sh}) ; 415(1700) .\end{array}$ & $1 \times 10^{-8}$ \\
\hline $\mathrm{Ni}(\mathrm{cpd})_{2} \mathrm{I}_{0.97}$ & $\begin{array}{l}785(37500) ; 645(7500) ; 510(6950) ; 385(8725) ; \\
345(9950)\end{array}$ & $7 \times 10^{-7}$ \\
\hline 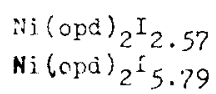 & $\begin{array}{l}488(1700, \mathrm{sh}) ; 435(4300, \mathrm{sh}) ; 388(5025) \\
707(16000)^{\mathrm{b}} ; 368(48300)\end{array}$ & $\begin{array}{l}4 \times 10^{-5} \\
1 \times 10^{-7}\end{array}$ \\
\hline
\end{tabular}

a. Absorption in $\mathrm{nm}$, extinction coefficient in parentheses, $\mathrm{sh}=$ shoulder

b. Acetone as solvent.

from its solution spectrum [9]. This suggests $d$ (metal)$\pi$ (ligand) or $\pi-\pi$ (ligand) interactions between adjacent molecules in the solid state. The iodine oxidation of $\mathrm{Ni}(\text { opd })_{2}$ may produce the "hole" either on metal- or ligand-centers and induce the conductive path which results the conductivity of these materials. As shown in Table 2, the pressed pellet conductivities of Ni(opd $)_{2} I_{x}$ are comparable to those of $\mathrm{Ni}(\mathrm{opd})_{2} \cdot \mathrm{Ni}(\mathrm{edt})_{2}$ (edt $=$ ethylenedithiolato) $\left(1.7 \times 10^{-3} \Omega^{-1} \mathrm{~cm}^{-1}\right)^{9}, \mathrm{Ni}(\mathrm{dpg})_{2} \mathrm{I}[12]$, and others [1].

The results of this study demonstrate the iodine oxidation of square planar $d^{8}$ complexes with highly unsaturated ligand is a viable synthetic route to highly conducting mixed valence materials. Further structural studies are in progress and necessary for (i) elucidating the form of the halogen (i.e. $\mathrm{I}_{2}, \mathrm{I}^{-}, \mathrm{I}_{3}{ }^{-}$or $\mathrm{I}_{5}{ }^{-}$) in these complexes, (ii) understanding of the electronic and conductive properties of these materials.

Acknowledgement-The authors wish to express their sincere gratitude to Prof. K. H. Houng for his help of X-ray powder patterns measurements and Dr. L. P. Hwang for obtaining EPR spectra. The work was supported by the National Science Council of the Republic of China, to which thanks are due.

\section{REFERENCES}

1. J. S. Miller and A. J. Epstein, Prog. Inorg. Chem. 20, 1 (1976), and Ref. therein

2. L. V. Interrante [Ed.], ACS Symp. Ser. No. 5, 1 (1975)

3. K. Krogmann, Angew. Chem. Int. Edn 8, 35 (1969).

4. J. L. Petersen, C. S. Schramm, D. R. Stojakovic, B. M. Hoffman and T. J. Marks, J. Am. Chem. Soc. 99, 286 (1977).

5. T. E. Phillips and B. M. Hoffman, J. Am. Chem. Soc, 99, 7734 (1977).

6. A. Gleizes, T. J. Marks and J. A. Ibers, J. Am. Chem. Soc. 97 , 3545 (1975)

7. J. S. Miller and C. H. Griffiths, J. Am. Chem. Soc. 99, 749 (1977).

8. A. L. Balch and R. H. Holm. J. Am. Chem. Soc. 88, 5201 (1966).

9. M. G. Miles and J. D. Wilson, Inorg. Chem. 14, 2357 (1975).

10. G. S. Hall and R. H. Soderberg, Inorg. Chem. 7, 2300 (1968),

11. R. Neiman and D. Kivelson, J. Chem. Phys. 35, 161 (1961).

12. A. E. Underhill, D. M. Watkins and R. Pethig, Inorg. Nucl Chem. Lett. 9, 1269 (1973). 